\title{
Theoretical Spectral investigation of a bioactive Benzenoid Isolated from Mimusops elengi
}

\author{
Asha A. Kale ${ }^{1}$, Navin Suryavanshi ${ }^{2}$, R. G. Sarawadekar ${ }^{2}$, \\ Nirmala R. Deshpande ${ }^{1}$, Jyoti P. Salvekar ${ }^{1}$ \\ 1. Dr. T. R. Ingle Research Laboratory, Dept. of Chemistry, S. P. College, Pune-411030, (India) \\ 2. Y. M. College, Bharati Vidyapeeth, Pune-411038, (India).
}

\begin{abstract}
The bioactive aromatic aldehyde, vanillin (3-methoxy 4-hydroxy benzaldehyde) is isolated from stem bark of the medicinal plant Mimusops elengi for the first time. Elucidation of structure is achieved with the help of spectral data derived from GC-MS, FTIR, ${ }^{1} H N M R$ and ${ }^{13}$ CNMR analysis. The structure of 3-methoxy 4-hydroxy benzaldehyde is examined by use of the HF (6-31G ${ }^{*}$ level), Density Functional Theory, DFT (6-31G ${ }^{*}$ level) and hybrid functional B3LYP. Using the optimized structure of this compound IR, ${ }^{1} H N M R$ and ${ }^{13} C N M R$ data is calculated and compared with the experimental data. The results are discussed in this article. It shows good relation between theoretically calculated and observed values for IR wave numbers. The chemical shifts are in good comparison for ${ }^{1} H N M R$ and ${ }^{13}$ CNMR spectra too.
\end{abstract}

Key words: 3-methoxy 4-hydroxy benzaldehyde, FTIR, NMR, HF (6-31G* level), DFT.

\section{INTRODUCTION}

Mimusops is a genus distributed in tropics of the Old World, North and Peninsular India and Andaman Islands. One of the species M. elengi L., is found in India. The tree attains large dimensions in moist evergreen forests of Western Ghats of Maharashtra, India. In Andaman, climate favors its height to 35 meters. It is planted as an avenue, shade tree and ornament in many parts of India ${ }^{1,2}$. It is a potent medicinal plant having historic importance. Literature survey revealed that all parts of the plant are used for treatment of various diseases. The flowers, fruits and bark are acrid, astringent, cooling and anthelmintic ${ }^{3}$. In Ayurveda, preparation of Mimusops "Bakuladya Taila" is applied on gums and teeth for strengthening. Leaves are used as an antidote for snakebite 4

Nutritive value of leaves has been evaluated ${ }^{5}$. Stem bark is used as a gargle for odontopathy, inflammation and bleeding of gums. Tender stems are used as tooth brushes ${ }^{2}$. It is applied as antipyretic, analgesic, tonic, febrifuge and helpful in urethrorrhoea, cystorrhoea, diarrhoea and dysentery ${ }^{3}$. Anthelmintic activity of bark was reported ${ }^{7}$. Bark and seed coat are used for strengthening the gums. "Vajradanti", one of the famous Indian tooth powder is composed of it. Tree is lopped for medium quality fodder. Flowers are constituents of cosmetic formulations. The bark is used as dye ${ }^{\mathbf{8}, \boldsymbol{9}}$. Plant is potential source for hydrocarbons \& phytochemicals ${ }^{10}$.

Vanillin is a phenolic aldehyde with molecular formula $\mathrm{C}_{8} \mathrm{H}_{8} \mathrm{O}_{3}$. It is the primary component of vanilla bean, roasted coffee and Chinese red pine ${ }^{11}$. Vanillin has been used as a chemical intermediate in the production of pharmaceuticals and other fine chemicals ${ }^{\mathbf{1 2}}$. Vanillin is an effective antimicrobial agent in fruit purees ${ }^{13,14}$. Mode of antimicrobial action of vanillin against Saccharomyces cerevisiae, Zygosaccharomyces rouxii, Debaryomyces hansenii and Z. bailii ${ }^{15}$, Escherichia coli, Lactobacillus plantarum and Listeria innocua. is studied $^{16,17}$. Its antifungal properties are established.

Present study deals with isolation of 3-methoxy, 4-hydroxy benzaldehyde (vanillin) from acetone extract of stem bark for the first time. The structure of this bioactive component was elucidated with the help of modern spectral techniques. The important features of the spectral data were compared with the reported. The computerized programme 'Gaussian 09' DFT (B3LYP/6-31G' and RHF (6-31G') was used for theoretical calculations of wave numbers for IR and chemical shifts for ${ }^{1} \mathrm{HNMR}$ and ${ }^{13} \mathrm{CNMR}$ spectra. Theoretical and experimental values are in good agreement. The verification of spectral data using computational chemistry is performed for the first time for the titled compound, isolated from natural source. 


\section{MATERIALS AND METHODS}

Air shade dried, pulverized plant material $(50 \mathrm{~g})$ was refluxed in acetone $(150 \mathrm{ml})$ for 12 hours. Solvent was collected under reduced pressure to furnish a bioactive sticky mass. Bio-guided separation of the crude mass was performed. Broad fractionation was achieved using nonpolar hexane to polar methanol solvents. Seven fractions were collected and tested for their bioactivity. The active fraction was rechromatographed on silica gel to provide nine sub-fractions. Fractions were monitored by TLC and bioactivity was examined. Bioactive fraction was purified by repeated crystallization using mixed solvent system of hexane: ethyl acetate to capitulate white crystalline solid $(0.29 \%)$, vanillin. Structure was confirmed by modern spectral analysis. IR spectra were recorded on FTIR 3700 spectrophotometer Schimadzu in the range $4000-400 \mathrm{~cm}^{-1}$. Proton NMR and ${ }^{13} \mathrm{CNMR}$ were recorded on Varian MR-400MHz in $\mathrm{CDCl}_{3}$.

\section{COMPUTATIONAL DETAILS}

The experimental spectral data was compared with the theoretically calculated values obtained from the computerized programme 'Gaussian 09' DFT(B3LYP/6-31G ${ }^{*}$ and RHF (6-31G') levels of theory. The structure confirmed by spectral analysis was provided to the computerized programme. It shows optimized parameters for IR, ${ }^{1} \mathrm{HNMR}$ and ${ }^{13} \mathrm{CNMR}$ for the molecule. A restricted Hartree Fock SCF calculation was performed using Pilay DIIS+ Geometric Direct Minimization. The wave number values computed theoretically contain known systematic error due to the negligence of electron correlation ${ }^{\mathbf{1 8}}$. Therefore, the scaling factor 0.90 is used for $\mathrm{HF} / 6-31 \mathrm{G}^{*}$ set for calculation of IR wave numbers.

\section{RESULTS AND DISCUSSION}

This compound is isolated from acetone extract of stem bark. It is in the form of white shining, needleshaped crystals. It shows sharp melting nature at $82^{\circ} \mathrm{C}$, which matches with the authentic sample. It shows $98 \%$ purity by Gas chromatogram. The GC-MS (exhibits $95 \%$ similarity index factor (NIST \& WILEY Libraries) for the occurrence of 4-hydroxy, 3-methoxy benzaldehyde (vanillin). The mass spectrum of the compound demonstrates molecular ion peak at $m / z, 152(77 \%)$ and $m / z, 153[\mathrm{M}+1]^{+}(97 \%)$. A characteristic base peak at $\mathrm{m} / \mathrm{z} 151\left[(\mathrm{M}-1)^{+}(100 \%)\right]$ indicates the presence of an aldehydic group. Fragmentation pattern is in agreement with the structure and suggests molecular formula to be $\mathrm{C}_{8} \mathrm{H}_{8} \mathrm{O}_{3}$

IR spectrum (Table 1) displays a characteristic absorption frequency at $3460,3374 \mathrm{~cm}^{-1}(-\mathrm{O}-\mathrm{H}$ stretching). A peak is noted at $2728 \mathrm{~cm}^{-1}$ for aldehydic $\mathrm{C}-\mathrm{H}$ stretching of $(\mathrm{H}-\mathrm{C}=\mathrm{O})$ group. Conjugated aldehydic carbonyl frequency is recorded at $1715 \mathrm{~cm}^{-1}$. Frequencies at $1605 \mathrm{~cm}^{-1}, 1549 \mathrm{~cm}^{-1}$ and $1462 \mathrm{~cm}^{-1}$ detect presence of an aromatic ring. Presence of methyl group is noted by frequency at $1377 \mathrm{~cm}^{-1}$; bands at $1215 \mathrm{~cm}^{-1}$ and 1022 $\mathrm{cm}^{-1}$ are detected for $(\mathrm{C}-\mathrm{O}-\mathrm{C})$, etherial group. All frequencies are well matched with authentic sample.
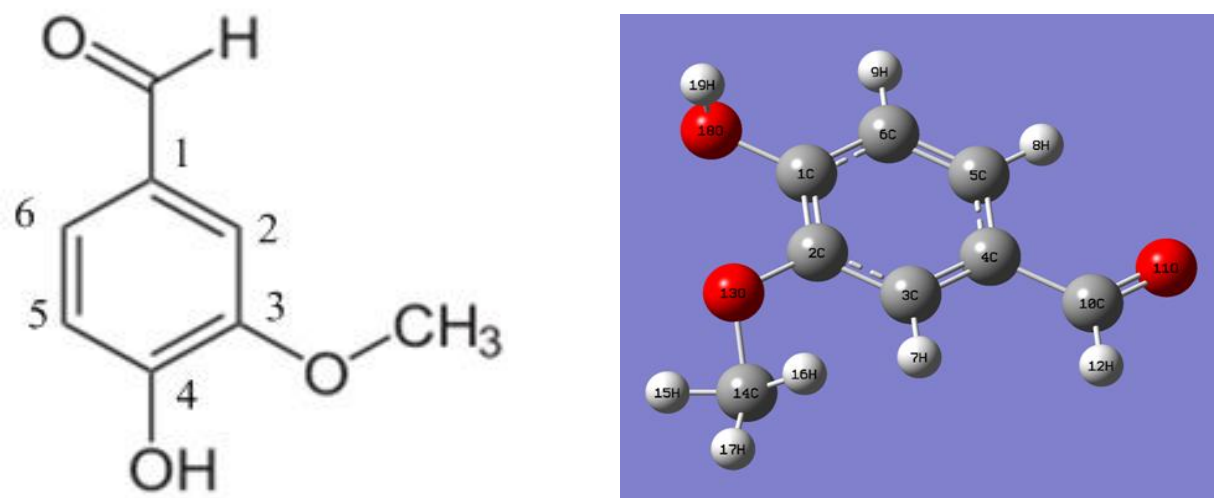

Fig 1 Structure of Vanillin

${ }^{1} \mathrm{H}$ NMR spectrum (Table 2) displays the most downfield sharp and strong singlet for aldehydic proton at $\delta$ 11.90. Chemical shift at $\delta 7.62$ represent aromatic protons ( $\underline{\mathrm{H}}-2$ and $\underline{\mathrm{H}}-6)$. Aromatic proton $\underline{\mathrm{H}}-5$ is assigned at $\delta$ 7.05. A peak is designated at $\delta 3.09$ for methoxy methyl protons.

${ }^{13}$ CNMR (Table 2) spectrum exhibits a characteristic downfield singlet at $\delta 190.29$ for aldehydic carbonyl carbon. A singlet is appeared at $\delta 161.40$ for C-4 carbon atom possessing hydroxy group. A strong singlet is noticed at $\delta 139.57$ due to C-3 aromatic carbon having methoxy group. A singlet is seen at $\delta 138.65$ for aromatic carbon carrying aldehydic group. Three aromatic doublets are displayed at $\delta 136.58, \delta 124.50$ and $\delta 119.17$ for C-5, C-2 and C-6 respectively. An upfield quartet is recognized at $\delta 54.50$ for methoxy methyl carbon atom. 


\section{SPECTRAL DATA CALCULATIONS BY DENSITY FUNCTIONAL THEORY (DFT)}

Theoretical calculations were carried out with Gaussian 09 program using the DFT (B3LYP/ 6-31 G* level) and RHF (6-31 $\mathrm{G}^{*}$ ) levels of theory to predict the molecular structure and wave numbers in IR region. ${ }^{1} \mathrm{HNMR}$ and ${ }^{13} \mathrm{CNMR}$ chemical shifts are calculated by employing geometry optimization and compared with experimental data. It shows good relation between theoretically calculated IR wave numbers and observed values for IR data. The data for wave numbers and their assignments are denoted (Table 1). The chemical shifts are in good comparison for ${ }^{1} \mathrm{HNMR} \&{ }^{13} \mathrm{CNMR}$ spectra. Aldehydic proton shows downfield shift by DFT calculations, which is in agreement with experimental and reported data. The numbers assigned to atoms are as per the computerized 'Gaussian 09' programme (Fig 1). Aromatic protons $\underline{\mathrm{H}}-7$ \& $\mathrm{H}-8$, ortho to aldehydic, function show downfield shifts. Aromatic proton $\underline{\mathrm{H}}-7$ is most downfield due to disturbed planarity of ortho substituted methoxy group, where O-Me group indicates that $-\mathrm{I}>+\mathrm{M}$ effect. Meta substituted $\underline{\mathrm{H}}-\mathbf{9}$ proton is observed with same chemical shifts like ortho-substituted. Chemical shift of hydroxy group depends on concentration, temperature and solvent used, which indicates a little deviation in theoretical and experimental value. Same is the reason for difference of values for $\underline{\mathrm{H}}-19$. The details are denoted (Table 2). Molecular structure used for these calculations is given (Fig 1).

Table -1 FTIR Wave numbers \& Assignments

\begin{tabular}{|l|l|l|l|l|}
\hline Sr. No. & Calc. $\left(\mathbf{c m}^{-1}\right)[\mathbf{H F}]$ & Intensity & Expt. $\left(\mathbf{c m}^{-1}\right)$ & \multicolumn{1}{|l|}{ Assignment } \\
\hline 1 & 588.789 & 14.4 & 590.24 & C-H Bending o.p.(C5-H8, C10-H12) \\
\hline 2 & 634.329 & 25.25 & 636.53 & Skeletal deformation i.p. \\
\hline 3 & 706.329 & 26.75 & 709.83 & C=C Bending (C1-C2) \\
\hline 4 & 734.454 & 70.2 & 736.83 & C-O Stretching (C1-O18, C2-O13) \\
\hline 5 & 851.22 & 62.71 & 832.26 & C-H Bending o.p. (C6-H9, C5-H8) \\
\hline 6 & 870.975 & 59.88 & 860.28 & C-C Stretching (C4-C10) \\
\hline 7 & 1016.73 & 10.05 & 1022.11 & C-H Bending o.p. (C6-H9, C5-H8) \\
\hline 8 & 1137.825 & 52.44 & 1128.39 & C-C Stretching i.p. \\
\hline 9 & 1151.1 & 157.16 & 1159.26 & C-H Bending i.p. \\
\hline 10 & 1194.174 & 303.38 & 1203.62 & C-O Stretching (C14-H13) \\
\hline 11 & 1276.209 & 12.8 & 1271.13 & C=C Stretching \\
\hline 12 & 1299.285 & 15.72 & 1296.21 & C=C Stretching \\
\hline 13 & 1399.734 & 83.27 & 1396.51 & C=O Stretching (C10-O11) \\
\hline 14 & 1506.78 & 19.01 & 1512.24 & C=C Stretching (C6=C5, C3=C4) \\
\hline 15 & 1640.052 & 31.81 & 1648.48 & C=C Stretching (C1=C2, C3=C4) \\
\hline 16 & 2906.766 & 141.51 & 2947.33 & C-H Stretching Meth. Gr. (unsymm.) [C14- H17] \\
\hline 17 & 3020.859 & 1.23 & 3028.41 & C-H Stretching (unsymm.) [C6- H9, C5-H8] \\
\hline 18 & 3150.594 & 122.98 & 3188.87 & C-HStretching Meth. Gr. (unsymm.) [C14- H15, H17] \\
\hline 19 & 3483.369 & 130.609 & 3460.67 & O-H Stretching (O18-H19) \\
\hline
\end{tabular}

Table- 2 Chemical Shifts of ${ }^{1} \mathrm{HNMR}$ and ${ }^{13} \mathrm{C}$ NMR in $\mathrm{CDCl}_{3}$

\begin{tabular}{|c|c|c|c|c|c|c|c|c|}
\hline Sr. No & Atom & $\begin{array}{l}\text { Calc. } \\
\text { (ppm) }\end{array}$ & $\begin{array}{l}\text { Exp. } \\
\text { (ppm) }\end{array}$ & Reported (ppm) & Atom & $\begin{array}{l}\text { Calc. } \\
\text { (ppm) }\end{array}$ & $\begin{array}{l}\text { Exp. } \\
\text { (ppm) }\end{array}$ & $\begin{array}{l}\text { Reported } \\
(\mathrm{ppm})\end{array}$ \\
\hline 1 & H-12 & 10.21 & 9.84 & 10.90 & C-10 & 210.89 & 191.27 & 191.0 \\
\hline 2 & H-7 & 6.96 & 7.45 & 7.65 & C-1 & 133.32 & 161.40 & 154.5 \\
\hline 3 & H-8 & 6.91 & 7.05 & 7.03 & C-2 & 144.12 & 139.57 & 149.7 \\
\hline 4 & H-9 & 6.17 & 7.05 & 7.05 & C-3 & 112.90 & 124.50 & 125.0 \\
\hline \multirow[t]{4}{*}{5} & H-19 & 1.43 & 3.49 & 3.09 & $\mathrm{C}-4$ & 122.90 & 138.65 & 130.5 \\
\hline & & & & & C-5 & 110.64 & 136.58 & 110.6 \\
\hline & & & & & C-6 & 111.05 & 119.17 & 117.4 \\
\hline & & & & & C-14 & 54.5 & 80.78 & 56.1 \\
\hline
\end{tabular}

Table-3 B3LYP optimized geometrical parameters

\begin{tabular}{|c|c|c|c|c|c|}
\hline Bond length & Ao & Bond angle & (o) & Bond angle & (o) \\
\hline $\mathrm{C} 1-\mathrm{C} 2$ & 1.35520 & $\mathrm{C}_{1} \mathrm{C}_{2} \mathrm{C}_{3}$ & 120 & $\mathrm{H}_{12} \mathrm{C}_{10} \mathrm{C}_{4}$ & 120 \\
\hline $\mathrm{C} 1-\mathrm{C} 6$ & 1.4014 & $\mathrm{C}_{4} \mathrm{C}_{3} \mathrm{C}_{2}$ & 120 & $\mathrm{C}_{1} \mathrm{C}_{2} \mathrm{O}_{13}$ & 120 \\
\hline $\mathrm{C} 3-\mathrm{C} 4$ & 1.35520 & $\mathrm{C}_{5} \mathrm{C}_{4} \mathrm{C}_{3}$ & 119.99 & $\mathrm{C}_{14} \mathrm{O}_{13} \mathrm{C}_{2}$ & 109.47 \\
\hline $\mathrm{C} 2-\mathrm{C} 3$ & 1.4014 & $\mathrm{C}_{2} \mathrm{C}_{3} \mathrm{H}_{7}$ & 120 & $\mathrm{H}_{15} \mathrm{C}_{14} \mathrm{O}_{13}$ & 82.57 \\
\hline $\mathrm{C} 4-\mathrm{C} 5$ & 1.4014 & $\mathrm{C}_{4} \mathrm{C}_{5} \mathrm{H}_{8}$ & 120.50 & $\mathrm{H}_{16} \mathrm{C}_{14} \mathrm{O}_{13}$ & 83.95 \\
\hline $\mathrm{C} 4-\mathrm{C} 10$ & 1.5400 & $\mathrm{C}_{5} \mathrm{C}_{6} \mathrm{H}_{9}$ & 120 & $\mathrm{H}_{17} \mathrm{C}_{14} \mathrm{O}_{13}$ & 140.09 \\
\hline-- & -- & $\mathrm{C}_{10} \mathrm{C}_{4} \mathrm{C}_{3}$ & 120 & $\mathrm{C}_{2} \mathrm{C}_{1} \mathrm{O}_{18}$ & 119.99 \\
\hline-- & -- & $\mathrm{O}_{11} \mathrm{C}_{10} \mathrm{C}_{4}$ & 120 & $\mathrm{H}_{19} \mathrm{O}_{18} \mathrm{C}_{1}$ & 109.47 \\
\hline
\end{tabular}




\section{ACKNOWLEDGEMENT}

Authors are thankful to The Head, Department of Chemistry and The Principle, S. P. College, Pune for providing the experimental facilities.

\section{REFERENCES}

[1.] Wealth of India, Raw Materials Vol.6, 383, CSIR, New Delhi, India, 1962.

[2.] Database on Med. Plants Used in Ayurveda Vol. 1 65, 2000.

[3.] P. P. Joy, J. Thomas, Samuel Mathew, Baby P. Medicinal Plants, 126,1998.

[4.] S.G. Joshi, Medicinal Plants, Oxford and IBH Publ. Co. Pvt. Ltd., 362, 2000.

[5.] Chakraborti, N. ; Madal, L.; Banerjee, G. C. Indian Vet. J., 65 (2), 145-9, 1988.

[6.] Mandal, B.; Maity, C. R., Acta Aliment, 20 (2), 103-7 , 1991

[7.] Mali R.G., Mahajan S.G. and Mehta A.A.; Phcog Mag. 3 (10), 73-75, 2007

[8.] The Useful Plants of India, National Inst. of Sci. Commu.,CSIR, , 375, 2000

[9.] Bhuyan, R.;et. al.,Indian J. of Fibre \& Textile Res., 29 (4), 470-476, 2004.

[10.] Kalita, D.; Saikia, C. N., Bioresource Technology, 92 (3), 219-227, 2004

[11.] Blank, et. al., Untersuchung und-Forschung A, 195 (3): 239-245, 1992.

[12.] Guth,;.Zeitschrift für Leben.-Untersu.-Forsch. A 196 (1): 22-28, 1995.

[13.] CerruttiI P., Alzamora S. M. Journal of Food Sci., 62, 608-610, 1997,

[14.] H.P.Vasantha Rupasinghe, Jeanine, doi:10.1016/j.foodres.2005.11.005.

[15.] Patricia Cerrutti , Intern. J.of Food Microbio.y, 29, (2-3), 379-386, 1996

[16.] Fitzgerald DJ, Stratford M, J. Appl Microbiol. 97(1):104-13, 2004

[17.] López-Malo, S.M. Alzamora, Food Res. Intern., 39, 5, 575-580, 2006.

[18.] A. Cukuovali, E. Tas, M. Ahmedzad, Synth. Rect. Inorg., Met. Org. Nano Mat. Chem., 27(5), 1997, 639-646. 